\title{
Self-Efficacy in Newly-Hired Child Welfare Workers
}

\author{
Donna Cherry \\ Bruce Dalton \\ Angela Dugan
}

\begin{abstract}
Child abuse and neglect in the United States resulted in 676,569 reports in 2011 (U.S. Dept. of Health and Human Services, 2012). Workers in this field struggle with low pay, high caseloads, inadequate training and supervision, and risk of violence, all of which contribute to worker burnout and poor worker retention rates. Worker selfefficacy is predictive of worker retention, job performance, and persistence in this difficult field. This paper reports the development of a new measure of self-efficacy from a sample of 395 child welfare workers. Factor analysis revealed two domains of selfefficacy, direct practice and indirect practice, which can be modestly predicted by worker characteristics upon hire and the training program the workers attend. Worker selfefficacy can be used to identify vulnerable workers who may be especially in need of strong supervisory support as well as understand who to target for recruitment. A review of the literature of self-efficacy in child welfare workers is included.
\end{abstract}

Keywords: Child welfare, self-efficacy, Title IV-E

Child welfare workers embrace one of the most challenging and stressful careers in social services. They serve a population of children who have suffered neglect, physical abuse, and sexual abuse, numbering 676,569 in 2011 (U.S. Dept. of Health and Human Services, 2012). Negative job characteristics such as low pay, high caseloads, inadequate training and supervision, conflicting roles, and risk of violence all contribute to worker burnout (DePanfilis \& Zlotnik, 2008; Faller, Grabarek, \& Ortega, 2010; McGowan, Auerbach, \& Strolin-Goltzman, 2009; Morazes, Benton, Clark, \& Jacquet, 2010). It is no surprise, then, that retention rates are poor, with national turnover rates reported at 30$40 \%$ (U.S. General Accounting Office, 2003). These high turnover rates are generally higher in the first few years of employment (Balfour \& Neff, 1993; Curry, McCarragher, \& Dellman-Jenkins, 2005; Smith, 2005).

In the interest of child well-being it is imperative to develop and retain competent child welfare workers in spite of contextual challenges, and self-efficacy is one important way to do so. Self-efficacy is related to job satisfaction, job retention, and job performance and can be influenced by supervisor support (Chen \& Scannapieco, 2010; Dickinson \& Painter, 2009; Ellett, 2009; Judge \& Bono, 2001, Stajkovic \& Luthans, 1998). Given that turnover of child welfare workers is a substantial issue and that selfefficacy is an important worker characteristic, it would be useful to investigate the level of self-efficacy of child welfare workers at the time they begin their jobs as well as explore the predictors of self-efficacy levels. Understanding worker self-efficacy can be used to recognize which workers are more vulnerable and may be especially in need of

Donna Cherry, Ph.D., is an Assistant Professor and Bruce Dalton, Ph.D., is a Professor, both in the Department of Social Work, and Angela Dugan is a Doctoral Fellow in Early Childhood Education, all at East Tennessee State University in Johnson City, TN.

Copyright (C) 2014 Advances in Social Work Vol. 15 No. 2 (Fall 2014), 318-333 
strong supervisory support as well as to understand whom to target for recruitment. A review of the literature regarding self-efficacy in child welfare workers is presented in the next section.

\section{Self-Efficacy}

Self-efficacy refers to "people's belief in their capacities to mobilize the motivation, cognitive resources, and courses of action needed to exercise control over given events" (Ozer \& Bandura, 1990, p. 472). In other words, although self-efficacy does not directly change individuals' capabilities, they may show more perseverance and effort when faced with difficult situations due to the control and sense of mastery they feel (Bandura, 1997; Lazarus \& Folkman, 1984; Liu, Siu, \& Shi, 2010). More specifically, studies indicate that people with high self-efficacy use more problem-focused coping as compared to the emotion-focused coping employed by those with low self-efficacy; further, problemfocused coping is related to less stress, both physical and psychological (see Semmer, 2003 for review). By extension, those with higher self-efficacy are more likely to be successful and therefore satisfied with their work (Judge, Locke, Durham, \& Kluger, 1998). Numerous studies in other fields also have found that high self-efficacy is related to greater job satisfaction, better job performance, lower job burnout, and better wellbeing, as compared to low self-efficacy (e.g. Bandura, 1997; Grau, Salanova, \& Peiro, 2001; Judge \& Bono, 2001; Pinquart, Juang, \& Silbereisen, 2003; Schyns \& von Collani, 2002; Siu, Lu, \& Spector, 2007; Stajkovic \& Luthans, 1998).

Self-efficacy as a focus of child welfare research is quite limited to date. Descriptively, Fox, Miller, and Barbee (2003) evaluated newly trained child welfare employees across 26 job duties reflecting basic competency training. Barbee and colleagues (2009) subsequently used the same indicators to evaluate new IV-E-trained child welfare workers at 6 months and 2 years. In both studies and at all data collection points, workers rated themselves above the midpoint for self-efficacy. Murphy (2007) compared three groups of new child welfare workers: graduates of a IV-E program were compared to two non-IV-E comparison groups, one containing employees who had no training in social work and one containing employees with degrees in social work. Each group included both bachelor's and master's level workers and used a self-assessment measure comprised of 30 child welfare-related tasks. The average scores for each group were above the midpoint in this study as well. There were no statistically significant differences among the three groups nor were there any differences when comparing all social workers (both IV-E and non-IV-E) with non-social workers. Finally, Wehrmann, Shin, and Poertner (2002) also found high scores on self-report learning outcomes at the end of child welfare training; however and notably, scores had dropped six months later.

In child welfare worker retention studies, self-efficacy has been positively associated with intention to remain on the job as well as actual retention (Chen \& Scannapieco, 2010; Dickinson \& Painter, 2009; Ellett, 2009; Fryer, Miyoshi, \& Thomas, 1989). In a longitudinal study, Jones and Okamura (2000) assessed newly hired workers on selfperceived competency and retention, finding that high self-efficacy scores were associated with longer retention periods. Dickinson and Painter (2009) found that those 
who remained in child welfare felt more efficacious about their ability to have a positive influence in the lives of their clients.

Self-efficacy is related to job performance in a variety of fields. A meta-analysis $(N=$ 114 studies) of studies from a variety of fields found a significant correlation of .38 between self-efficacy and job performance. A significant moderator of the relationship was task complexity; as task complexity rose the strength of the relationship fell (Stajkovic \& Luthans, 1998). Collins-Camargo (2007) found child welfare worker selfefficacy to be related to job performance and also two child outcome indicators, timeliness of investigations and cases open over 12 months. While only one of these outcome indicators was desirable, it is the only study to date directly linking child welfare worker self-efficacy to case outcome.

A few studies have specifically considered environmental variables and self-efficacy. This is important since the working environment of child welfare agencies is often characterized by staff shortages, high caseloads, and other factors (U.S. General Accounting Office, 2003) that may reduce workers' beliefs that they can exercise control over their work lives. Ellett (2009) writes that child welfare is arguably the most difficult field in social work. To work in such a context it is important that individual workers have the personal characteristics that help them persevere in the interest of the children they serve, and sometimes workers may have to advocate for children within an unsupportive system. Workers need a strong belief in their ability to effect change in the client's situation in the face of opposition and long odds. In a study of public child welfare workers in California, McElroy (2002) related self-efficacy to a number of personal and agency-related characteristics. She found self-efficacy to be positively and significantly correlated with job satisfaction but not with supervisory support. Chen and Scannapieco (2010) also examined these variables but looked for interaction effects. They found that supervisory support was important but, specifically, it was more important for the retention of child welfare workers with low self-efficacy as compared to those with high self-efficacy. Also, whereas job satisfaction was positively correlated with self-efficacy, it was not a linear relationship: it had a stronger relationship for those with high self-efficacy. This study indicated that job satisfaction was not enough to compensate for low self-efficacy where there was also a perceived lack of supervisor support. These findings about the importance of environmental factors for child welfare workers with low self-efficacy are consistent with findings on employees in the broader literature (Appelbaum \& Hare, 1996).

In summary, self-efficacy in child welfare workers is related to retention, job satisfaction, job performance, and supervisory support. Further, it appears that selfefficacy may drop over time (Jones \& Okamura, 2000), suggesting that the experience of work or environmental factors influences self-efficacy in the workplace. This is consistent with the idea that self-efficacy is not a static personality trait: rather, it is malleable (Bandura, 1997). As such, and because turnover is higher within the first few years of employment, it would be useful to assess self-reported level of job preparedness (i.e., self-efficacy) of workers at the time they begin employment to know who may be more vulnerable to workplace culture. Since self-efficacy is domain-specific (Bandura, 1986b) and child welfare competencies cover a wide range of skills, it would also be 
useful to develop a scale of worker competencies and conduct a factor analysis to look for the presence of subfactors. Because recruiting and hiring workers with high levels of high self-efficacy is preferable, it would be useful to know what factors predict higher levels of self-efficacy.

The study in this paper uses a retrospective pretest. In Collins, Kim, and Amodeo's (2010) review of empirical studies of child welfare training, those with retrospective pretest designs were deselected for inclusion due to perceived weakness in design. Campbell and Stanley (1963) consider the retrospective pretest design to be inferior, though acceptable, when a longitudinal study is not possible. Pratt, McGuigan, and Katzev (2000) compared pretest-posttest methodology to retrospective pretest methods in a sample of 307 mothers in a prevention program. They found that in situations where response-shift bias is present (where, before training, participants do not understand the concept being measured and thus overestimate their abilities), retrospective pretests are more accurate measures of the change produced by training. This is also supported by Berger, Gunto, Rice, and Haley (1996) in a large study of 2,100 trainees in the field of hazardous waste handling. Those trainees who completed retrospective pre-test/posttest measures showed a larger change than those who completed concurrent pretest/posttest measures. In essence, those completing efficacy pretests may overestimate their skills because before training they don't know what they don't know. Retrospective pretests may be more accurate because after training the participants now know what they didn't know.

The goals of this study are to (1) develop a measure of job preparedness to assess worker confidence (aka self-efficacy) for child welfare job duties; (2) explore these levels of self-efficacy at the time workers begin their jobs; and (3) examine factors that predict self-efficacy. It is hypothesized that self-efficacy will be significantly predicted by worker characteristics.

\section{Methods}

\section{Design, Sample, and Data Collection}

The study reported here is from an evaluation of training preparedness of caseworkers employed by the Department of Children's Services (DCS) in a southeastern state. Bachelors-level workers are prepared in one of two methods: (1) through the Title IV-E Child Welfare Stipend Program or Certification Program, a university-agency collaboration in which social work students complete two child welfare classes and a one-semester full-time internship with DCS immediately prior to graduation; or (2) a 9Week Pre-service Training program in which training is delivered within DCS immediately prior to assuming job responsibilities.

The researchers used a cross-sectional design and surveyed the entire population of child welfare workers in a southeastern state hired in a particular time period. Workers were invited to participate via an email invitation and web link to an internet-based survey using SurveyMonkey. Data collection took place in two phases. In Phase 1, data were collected in 2009 from employees hired from 2004 to mid-2008; Phase 2 data collection took place in 2011 for employees hired from mid-2008 to early 2011. Two 
follow-up emails and an incentive in the form a drawing for a gift card were used to encourage participation. The research study methods were approved by the Institutional Review Board for Human Subjects prior to any data collection.

\section{Measures}

Participants completed the Level of Preparedness Scale (LOPS) in addition to education and employment variables.

(1) Education, experience and employment. Workers completed the following demographic items: education (undergraduate degree, graduate degree or working toward a graduate degree); length of employment (years and months); prior child welfare experience (yes/no); current position in DCS (team coordinator, case manager/family services worker 1, 2, 3, or 4, or other; and current work area (19 work areas, detailed in results). (Note: in order to protect the identity of workers, especially given the low prevalence of male workers and workers who are non-White, no other demographic variables were collected as it would have been easy to identify individual workers with this information along with current position and title).

(2) Level of Preparedness Scale (LOPS). The LOPS is a new scale designed to measure self-reported perception of the degree to which the worker felt prepared for a range of child welfare job duties at the time s/he began employment with DCS. Content for the LOPS came from a review of relevant training literature and input from child welfare trainers for the state. The LOPS went through an extensive review process. State foster care professionals reviewed a draft set of items for clarity, comprehensiveness, sensitivity, and practice relevance. A pool of 29 items was given with the following instructions: The following set of questions address job duties at DCS. As you read each question, think about what your level of personal preparedness was at the time you began employment with DCS. Please respond thoughtfully to each item. Each item is rated on a sixpoint scale from (5) excellent to (1) poor, and (0) not covered in training.

\section{Results}

Results are presented in three sections: (1) worker characteristics; (2) factorial structure and scores of the LOPS; and (3) results of linear regression analyses. Statistical analyses were completed utilizing IBM SPSS 21.

\section{New Worker Demographic Characteristics}

A total of $N=395$ workers participated for a response rate of $45.13 \%$. Although the intent was to survey only workers who had been on the job for 36 months or less, a few subjects reported much longer periods of employment. In order to better ensure the integrity of recall, these cases were deleted. For the remaining sample $(N=342)$, education was as follows: $37.5 \%(N=127)$ reported having an undergraduate degree in social work, $19.5 \%(N=66)$ were working toward an advanced degree and $24.0 \%(N=$ $82)$ had an advanced degree. Length of employment ranged from 0 to 35 months, $(M=$ 
$16.9, S D=9.58)$ and almost half of the sample $(48.2 \%)$ reported having prior child welfare experience. Most respondents went through the 9-Week Pre-service Training after hire $(N=319,80.8 \%)$ while the rest went through the Title IV-E program $(N=76$, 19.2\%). Other employment characteristics are summarized in Table 1.

Table 1. Current Employment Characteristics

\begin{tabular}{|c|c|c|}
\hline Current Position $(\mathrm{N}=342)$ & $\mathbf{N}$ & $\%$ \\
\hline Team Coordinator & 0 & 0 \\
\hline Team leader/Case Manager 4/Family Services Worker 4 & 7 & 2.0 \\
\hline Case Manager 3/Family Services Worker 3 & 9 & 2.6 \\
\hline Case Manager 2/Family Services Worker 2 & 201 & 58.8 \\
\hline Case Manager 1/Family Services Worker 1 & 78 & 22.8 \\
\hline Other & 42 & 12.3 \\
\hline Missing & 5 & 1.5 \\
\hline Total & 342 & 100.0 \\
\hline Current Work Area & $\mathbf{N}$ & $\%$ \\
\hline Child Protective Services/Multiple Response Services & 159 & 46.5 \\
\hline Social Services-Foster Care & 115 & 33.6 \\
\hline Juvenile Justice & 56 & 16.4 \\
\hline Social Services Adoption & 18 & 5.3 \\
\hline Non-Custodial Case & 13 & 3.8 \\
\hline Investigation & 10 & 2.9 \\
\hline Court & 8 & 2.3 \\
\hline Other & 7 & 2.1 \\
\hline Placement & 6 & 1.8 \\
\hline Continuous Quality Improvement & 4 & 1.2 \\
\hline Intake & 3 & 0.9 \\
\hline Administration Human Resources & 1 & 0.3 \\
\hline Supervision CPS & 1 & 0.3 \\
\hline Supervision Social Services & 1 & 0.3 \\
\hline Supervision-Juvenile Justice & 1 & 0.3 \\
\hline $\begin{array}{l}\text { Eligibility and Benefits; Financial Management; Legal; Security; } \\
\text { Well-being/Staff Health }\end{array}$ & 0 (each) & 0 \\
\hline Total & 403 & $n / a$ \\
\hline
\end{tabular}

Note: total responses are greater than number of subjects: subjects could check more than one work area. Percentages are calculated as a percent of total subjects $(\mathrm{N}=342)$, not total responses. 
The samples collected at Phase 1 and Phase 2 were compared. No significant differences were found between the groups on the percent working toward an advanced degree, having prior child welfare experience, or the total months of DCS employment. Significantly more respondents at Phase 2 were graduates of the Title IV-E program (9.5\% at Phase 1 and $36.4 \%$ at Phase $\left.2, X^{2}=42.2, d f=1, p<.001\right)$. This is likely because the Title IV-E program continued to grow during this time.

\section{LOPS Factorial Structure and Scores}

There were 10 cases with more than $20 \%$ missing data that were deleted. Of the remaining cases, there were five cases $(1.27 \%)$ with one missing item and two cases $(0.51 \%)$ with two missing items. Missing item values were replaced with the mean item score and rounded to the nearest whole number.

Of the original 29 items, five had a large response frequency of Not Covered in Training. These items were deleted after confirming with trainers that these items are not reliably part of the training curriculum. With remaining 24 variables, Not Covered in Training responses were recoded as "missing" before the exploratory factor analysis (EFA) was conducted. (Note: to assess the impact of this coding strategy, we also coded these responses as "poor" and conducted an EFA subsequent and identical to the procedure described below. Both coding approaches resulted in the same factor structure.)

An EFA was conducted to explore whether one or more dimensions underlie the item scores. EFA was used because the LOPS is a new measure and it was necessary to investigate the underlying factor structure (Fabrigar, Wegener, MacCallum, \& Strahan, 1999; Osborne, Costello, \& Kellow, 2008). Unweighted least squares with promax rotation was used for the factor analysis, the scree test was used to guide the number of factors, and the pattern matrix was used to guide interpretation of the factors. Bartlett's test of sphericity $\left[X^{2}(276, N=347)=6365.22, p<.001\right]$ and the Kaiser-Meyer-Olkin measure of sampling adequacy $(\mathrm{KMO}=.94)$ strongly supported the suitability of the items for factor analysis.

The scree test clearly indicated a two-factor solution. Although 22 of the items cleanly loaded on one of the two factors, two items were problematic. The item "working directly with persons who supervise you" had a loading of .39 and the item "maintaining your personal safety" had low and cross-loaded results (.39 and .30). EFA was recalculated deleting one item at a time and with no marked improvement to the remaining items. Therefore, both items were deleted.

EFA was conducted with the remaining 22 items $(N=333)$. Factor 1 contained 16 items, all loading at .48 or greater (see Table 2). All corrected-item total correlations were .62 or greater and Cronbach's alpha was $\alpha=.96$. The item content for this factor was comprised of Direct Practice knowledge and skills. Factor 2 contained six items, all loading at .57 or greater. All corrected-item total correlations were .60 or greater and Cronbach's alpha was $\alpha=.89$. The item content for this factor was comprised of Indirect Practice knowledge and skills. The total amount of variance accounted for by both factors was 60.3\% (Direct Practice 51.3\%; Indirect Practice 9.0\%) and the correlation between 
factors was $r=.61$. For each factor the potential score was 1.00 to 5.00. For LOPS/Direct Practice, the overall mean score was $M=3.73(S D=.68, N=374)$. For LOPS/Indirect Practice, the overall mean score was $M=3.05(S D=.84, N=347)$.

Table 2. Level of Preparedness Scale (LOPS) Items and Factor Loadings

\begin{tabular}{lrr}
\hline & $\begin{array}{r}\text { Factor 1 } \\
\text { Direct } \\
\text { Practice }\end{array}$ & $\begin{array}{r}\text { Factor } 2 \\
\text { Indirect } \\
\text { Practice }\end{array}$ \\
Items & 0.96 & -0.28 \\
\hline Building positive working relationships with families of diverse & & \\
backgrounds & 0.96 & -0.16 \\
Partnering with families & 0.94 & -0.24 \\
Building positive working relationships with families & 0.86 & -0.05 \\
Developing a working agreement with a family & 0.74 & 0.15 \\
Planning with family teams for the child's safety & 0.73 & 0.17 \\
Planning with family teams for the child's well-being & 0.73 & 0.10 \\
Asking appropriate questions during all contacts with a family & 0.69 & 0.16 \\
Planning with family teams for long-term permanency & 0.66 & 0.10 \\
Building positive working relationships with community agencies & 0.65 & 0.01 \\
Remaining respectful during all contacts with a family & 0.64 & 0.11 \\
Applying the Best Practice guidelines (The Practice Wheel)* & 0.64 & 0.15 \\
Working effectively with children and youth of different ages & 0.60 & 0.18 \\
Being aware of different parenting strategies & 0.54 & 0.34 \\
Developing an appropriate case plan with the family based on identified & & \\
strengths and needs & 0.53 & 0.35 \\
Assessing signs of safety and risk, and making accurate determinations & 0.48 & 0.30 \\
Identifying indicators of abuse and neglect & -0.23 & 0.99 \\
Understanding the steps involved in closing a case & 0.05 & 0.74 \\
Understanding the steps involved in transferring a case & 0.10 & 0.63 \\
Understanding the law as related to child welfare practice & 0.09 & 0.63 \\
Knowing appropriate time frames pertaining to your specific duties & 0.15 & 0.57 \\
Writing/updating a functional assessment & & \\
Being able to document all case activities in a professional manner & 0.53 \\
\hline *This item reflects the agency's internally designated Best Practices, including a best practice referred to \\
as The Practice Wheel. & & \\
\hline
\end{tabular}




\section{Linear Regression Analyses}

Two linear regression models were used to explore relationships between a number of predictor variables and the two LOPS subfactors. The independent variables included Length of Employment, computed in months; Training Program, coded as 9-Week Preservice (2), Title IV-E (1); Undergraduate degree, recoded as Social Work (2), All Other (1); Having an Advanced Degree, coded Yes (2), No (1); Working toward an Advanced Degree, coded Yes (2), No (1); and Prior Child Welfare Experience, coded Yes (2), No (1). No other demographic variables were available for inclusion in these analyses. All of these variables were regressed simultaneously in separate models with LOPS/Direct Practice and LOPS/Indirect Practice as the dependent variables. For LOPS/Direct Practice, the overall model was significant $F(6,307)=5.31, p<.001$. The significant predictors for preparedness included length of employment (longer employment was associated with a lower level of preparedness), working toward an advanced degree, and having prior work experience (see Table 3). The model accounted for $9.4 \%$ of the variance in level of preparedness. For LOPS/Indirect Practice, the overall model was significant $F(6,283)=3.58, p=.002$ and the significant variables were social work as an undergraduate degree (associated with a lower level of preparedness), receiving training through the 9-Week Pre-service program (associated with a lower level of preparedness), working toward an advanced degree, and having prior child welfare experience. This model accounted for $7.0 \%$ of the variance in level of preparedness.

Table 3. Linear Regression Results

\begin{tabular}{lcccccc}
\hline Variables & \multicolumn{2}{c}{ Model 1 - LOPS/Direct Practice } & \multicolumn{3}{c}{ Model 2 - LOPS/Indirect Practice } \\
& B & SE B & $\beta$ & B & SE B & $\beta$ \\
\hline Length of employment & -0.014 & 0.004 & $-0.201 * *$ & -0.004 & 0.005 & -0.042 \\
Training program & -0.115 & 0.124 & -0.071 & -0.516 & 0.161 & $-0.255^{* *}$ \\
Undergraduate degree & -0.146 & 0.105 & -0.104 & -0.366 & 0.137 & $-0.209^{* *}$ \\
Having an advanced degree & 0.065 & 0.091 & 0.04 & 0.02 & 0.119 & 0.010 \\
Working toward adv degree & 0.343 & 0.095 & $0.200^{* *}$ & 0.37 & 0.125 & $0.173^{* *}$ \\
Prior child welfare experience & 0.189 & 0.078 & $0.139^{* *}$ & 0.225 & 0.101 & $0.133^{*}$ \\
\hline
\end{tabular}

Note. $R^{2}=.094 ;{ }^{*} p \leq .05 ; * * p \leq .01 \quad$ Note. $R^{2}=.070 ;{ }^{*} p \leq .05 ; * * p \leq .01$

\section{Discussion}

The first objective of this study was to develop a new measure, the LOPS, designed to assess the degree to which new workers feel prepared for a number of job task items at the time they begin employment with DCS. The EFA conducted on these items resulted in two factors, Direct Practice and Indirect Practice, with high factor loadings, strong reliability, and strong content validity for the items associated with each subscale. The subscales provide the opportunity to approach and understand the data analysis with more specificity. 
The second objective was to explore these levels of self-efficacy at the time workers begin their jobs. For LOPS/Direct Practice employees reported self-efficacy above the scale median $(M=3.73, S D=.68)$ while for LOPS/Indirect Practice employees reported self-efficacy at the scale median $(M=3.03, S D=.84)$. Previous studies have found selfefficacy reported above the scale median (Barbee et al., 2009; Fox et al., 2003) across an entire set of worker competencies. This is the first time self-efficacy was measured in two domains and suggests that a clearer understanding of self-efficacy can be gained with this approach.

The third objective was to determine which factors are associated with a sense of task competency, or self-efficacy, among public child welfare workers. For LOPS/Direct Practice, three of these variables were significantly related to self-efficacy. First, the longer workers had been on the job, the less prepared they felt at the beginning of their employment. This finding may reflect that training effectiveness had gotten better over time, so that employees who had been through training closer to the time of the survey had a better quality of training for worker competencies as compared to those who had been through an older version of the training. However, the trainers reported that training had not changed. Further, because the data was collected in two phases, this interpretation would not be supported. Another explanation could be that, despite being instructed to think back to how prepared they felt at the time they began employment, subjects' recall was influenced by time on the job and their evolving perspectives of the difficulty of their jobs. In this case, the findings would be similar to Barbee et al. (2009) who found a decrease in the mean self-efficacy scores from six months to two years. This supports the literature indicating how difficult child welfare work is (Ellett, 2009) and that workers need to be supported on the job in order to maintain their confidence in their work. Chen and Scannapieco (2010) found that supervisory support is especially important for workers with low self-efficacy. Improving supervisor support overall and/or matching vulnerable workers with more supportive supervisors would be indicated as possible interventions to improvement retention.

Employees who had prior work experience or were working toward an advanced degree also were more likely to report higher levels of job preparedness. Prior child welfare experience has also been identified as a correlate of retention in other studies (Balfour \& Neff, 1993; also, see review by Zlotnick, DePanfilis, Daining, \& Lane, 2005), although it was not directly tied to self-efficacy in these studies. Nonetheless, the findings in the current study are consistent with the view that self-efficacy is malleable and can be increased in four ways: through mastery experiences (the most effective way), modeling coping strategies and practice, social persuasion with positive appraisals, and increasing physiological states that are read as signs of strength and invulnerability (Bandura, 1986a).

In terms of working toward an advanced degree, this would suggest that workers with the academic ability and ambition to pursue graduate education are more confident, possibly because they are better learners or are more persistent. Each of these qualities is consistent with aspects of self-efficacy (Bandura, 1997). Oddly, already having a graduate degree was not associated with higher levels of self-efficacy. It may be that workers who were currently pursuing a degree were doing so in fields more relevant to 
their child welfare work as compared to those who had already attained advanced degrees. Also, workers with graduate degrees may have brought more experience or a higher degree of critical thinking to their training and may therefore have been more conservative when evaluating their levels of preparedness.

For LOPS/Indirect Practice, four worker characteristics were significantly related to self-efficacy scores. As with LOPS/Direct Practice, working toward an advanced degree and having prior child welfare experience were both positively associated with higher levels of self-efficacy. In contrast to LOPS/Direct Practice scores, length of employment was not a significant predictor for Indirect Practice. This difference may be accounted for by the types of competencies that comprise LOPS/Indirect Practice. These are indirect practice skills that are arguably more knowledge-based (e.g., "understanding the steps involved in transferring a case") whereas the LOPS/Direct Practice skills are more practice-based (e.g., "partnering with families") and are skills that workers may feel they understand at the beginning of a job but feel less confident about their competency with time and the wide variety of clients they encounter.

Also significant were training program and undergraduate degree. Specifically, workers who were trained through the 9-Week Pre-service program felt less confident about Indirect Practice skills as compared to those who were Title IV-E graduates. Yet, workers with an undergraduate degree in social work also reported less confidence as compared to those with any other undergraduate degree. These findings seem contradictory in that all Title IV-E workers have a BSW degree. However, 20\% of the 9week trained workers reported social work as their undergraduate degree. As a follow-up analysis, we compared the LOPS/Indirect Practice scores of Title IV-E workers to the subset of 9-Week Pre-service workers with social work undergraduate degrees. The average scores of the Title IV-E workers $(M=3.19, S D=.80)$ were slightly above the midpoint and higher than those of the 9 -Week Pre-service Training $(M=2.89, S D=.87)$ and the difference was significant $t(117)=1.96, p=.05$. This finding suggests that a Title IV-E education (child welfare classes and a field placement in child welfare) better prepares social work students for indirect practice competencies. Further, the importance of type of training program for indirect practice but not direct practice, as shown in this study, adds to the literature that has compared worker self-efficacy between these programs. To date, the results are mixed: for example, whereas Jones and Okamura (2000) found that Title IV-E workers are more confident than non-Title IV-E workers, Murphy (2007) found no differences between groups. The current study suggests there may be subtleties that can be understood by evaluating subdomains of worker selfefficacy.

The results of this study suggest that prior child welfare experience and working toward an advanced degree are common predictors for higher levels of self-efficacy. Recruiting workers of this caliber would be an obvious effective strategy towards improving worker retention. However, this does not suggest that those who do not fit this profile should be avoided. Since environmental variables are influential, closer attention should be paid to these factors, especially supervisory support, for those workers who are more vulnerable. By extension, assessing self-efficacy of workers at the time they began 
employment in child welfare can help agencies better predict which workers need support.

The primary strengths of this research included a large sample and the development and use of a scale that, upon factor analysis, resulted in two highly reliable subscales supporting two separate domains of child welfare practice. Further, statistical analyses using linear regression identified worker characteristics that are associated with workrelated self-efficacy.

Weaknesses included the use of a non-probability sample and a non-validated measure. Also, because these data were gathered after workers were already working, the time lapse between training and data collection might have weakened the integrity of the data due to subject recall and confounding with practice experience.

Also problematic was the lack of additional demographic variables. Although excluding other variables was justifiable to assure confidentiality and increase subject participation in the study, the lack of additional demographic information limits generalizability. As well, it may somewhat account for the low R-squared values in both subfactor analyses.

Future research should address the limitations noted above. Specifically, it would be informative to capture worker self-efficacy immediately after the training and then again after 1-2 years in practice to better understand how work experience and environmental variables influence self-efficacy for subgroups (i.e., those with prior work experience and graduate degree aspirations). Also, given the relatively low amount of variance accounted for by each model, it is important to consider which variables may have been missing. Identification of these variables is important to increase the R-squared value in each model as this is an indicator of the goodness-of-fit of the models (Kutner, Nachtsheim, \& Neter, 2004). These may include demographic variables, as noted above, as well as environmental variables such as staff shortages, high caseloads, inadequate supervision, and others.

\section{Conclusion}

Overall, these findings suggest workers feel confident about their level of preparedness across a variety of child welfare competencies. However, self-efficacy varies across workers. It is influenced by prior work experience and is associated with the pursuit of graduate education for both direct and indirect practice skill domains, and by length of time on the job, undergraduate degree, and training program for specific domains of worker competencies. Since self-efficacy is related to competence and retention, and competent workers are critical for the well-being of children involved in the child welfare system, it is essential that we continue to learn more about factors that influence work-related self-efficacy prior to, and in the course of, child welfare employment. This knowledge is needed in order to recruit more strategically as well as monitor and intervene to maintain or improve self-efficacy in child welfare workers. 


\section{References}

Appelbaum, S. H., \& Hare, A. (1996). Self-efficacy as a mediator of goal setting and performance: Some human resource applications. Journal of Managerial Psychology, 11(3), 33-47.

Balfour, D., \& Neff, D. (1993). Predicting and managing turnover in human service agencies: A case study of an organization in crisis. Public Personnel Management, 22(3), 473-486.

Bandura, A. (1986a). Social foundations of thought and action: A social cognitive theory. Englewood Cliffs, NJ: Prentice-Hall.

Bandura, A. (1986b). The explanatory and predictive scope of self-efficacy theory. Journal of Social and Clinical Psychology, 4(3), 359-373.

Bandura, A. (1997). Self-efficacy: The exercise of control. New York, NY: W. H. Freeman and Co.

Barbee, A., Antle, B., Sullivan, D., Hall, C. J., Borders, K., \& Fox, S. (2009). Evaluation of an innovative social work education model: The Kentucky Public Child Welfare Certification Program (PCWCP). Journal of Social Work Education, 45(3), 427-444.

Berger, P. K., Gunto, S. J., Rice, C., \& Haley, J. V. (1996). Estimating the impact of health and safety training using the retrospective pretest design. Applied Occupational and Environmental Hygiene, 11(10), 1198-1203.

Campbell, D. T., \& Stanley, J. C. (1963). Experimental and quasi-experimental designs for research. Boston, MA: Houghton Mifflin Company.

Chen, S., \& Scannapieco, M. (2010). The influence of job satisfaction on child welfare worker's desire to stay: An examination of the interaction effect of self-efficacy and supportive supervision. Children and Youth Services Review, 32, 482-486.

Collins, M. E., Kim, S. H., \& Amodeo, M. (2010). Empirical studies of child welfare training effectiveness: Methods and outcomes. Child \& Adolescent Social Work Journal, 27(1), 41-62. doi:10.1007/s10560-009-0190-0

Collins-Camargo, C. (2007). A study of the relationship between effective supervision, organizational culture promoting evidence-based practice, worker self-efficacy, and outcomes in public child welfare (Unpublished doctoral dissertation). University of Kentucky, Lexington.

Curry, D., McCarragher, T., \& Dellman-Jenkins, M. (2005). Training, transfer, and turnover: Exploring the relationship among transfer of learning factors and staff retention in child welfare. Children and Youth Services Review, 27, 931-948.

DePanfilis, D., \& Zlotnik, J. (2008). Retention of front line staff in child welfare: A systematic review of research. Children and Youth Services Review, 30, 995-1008.

Dickinson, N. S., \& Painter, J. S. (2009). Predictors of undesired turnover for child welfare workers. Child Welfare, 88(5), 187-208. 
Ellett, A. J. (2009). Intentions to remain employed in child welfare: The role of human caring, self-efficacy beliefs, and professional organizational culture. Children and Youth Services Review, 31, 78-88.

Fabrigar, L. R., Wegener, D.T., MacCallum, T. C., \& Strahan, E. J. (1999). Evaluating the use of exploratory factor analysis in psychological research. Psychological Methods, 4(3), 272-299.

Faller, K., Grabarek, M., \& Ortega, R. (2010). Commitment to child welfare work: What predicts leaving and staying? Children \& Youth Services Review, 32(6), 840-846. doi:10.1016/j.childyouth.2010.02.003

Fox, S. R., Miller, V. P., \& Barbee, A. P. (2003). Finding and keeping child welfare workers: Effective use of training and professional development. Journal of Human Behavior in the Social Environment, 7(1-2), 67-81.

Fryer, G. E., Miyoshi, T. J., \& Thomas, P. J. (1989). The relationship of child protectionworker attitudes to attrition from the field. Child Abuse \& Neglect, 13, $345-$ 350 .

Grau, R., Salanova, M., \& Peiro, J. M. (2001). Moderator effects of self-efficacy on occupational stress. Psychology in Spain, 5, 63-74.

Jones, L. P. \& Okamura, A. (2000). Reprofessionalizing child welfare services: An evaluation of a Title IV-E training program. Research on Social Work Practice, 10, 607-621.

Judge, T. A., \& Bono, J. E. (2001). Relationship of core self-evaluations traits-selfesteem, generalized self-efficacy, locus of control, and emotional stability-with job satisfaction and job performance: A meta-analysis. Journal of Applied Psychology, 86(1), 80-92.

Judge, T. A., Locke, E. A., Durham, C. C., \& Kluger, A. N. (1998). Dispositional effects on job and life satisfaction: The role of core evaluations. Journal of Applied Psychology, 83(1), 17-34. doi:10.1037/0021-9010.83.1.17

Kutner, M. H., Nachtsheim, C., \& Neter, J. (2004). Applied linear regression models $\left(5^{\text {th }}\right.$ ed.). Boston, MA: McGraw-Hill/Irwin.

Lazarus, R. S., \& Folkman, S. (1984). Stress, appraisal, and coping. New York, NY: Springer.

Liu, J., Siu, O., \& Shi, K. (2010). Transformational leadership and employee well-being: The mediating role of trust in the leader and self-efficacy. Applied Psychology: An International Review, 59(3), 454-479.

McElroy, K. L. (2002). Factors associated with high self-efficacy among California's public child welfare workers (Unpublished master's thesis). California State University, Los Angeles. Retrieved from http://lp.ncdownloader.com/EBook1/?q=McElroy $\% 20$ Self $\% 20$ efficacy $\% 20$ thesis $\% 2$ 0final $\% 20 \mathrm{doc}$ 
McGowan, B., Auerbach, C., \& Strolin-Goltzman, J. (2009). Turnover in the child welfare workforce: A different perspective. Journal of Social Service Research, 35(3), 228-235. doi:10.1080/01488370902900782

Morazes, J., Benton, A., Clark, S., \& Jacquet, S. (2010). Views of specially-trained child welfare social workers. Qualitative Social Work, 9(2), 227-247. doi:10.1177/1473325009350671

Murphy, S. R. (2007). Evaluation of the Title IV-E/426 program: A comparison study of the 2004 federally-funded social work education program for child welfare workers in Georgia (Unpublished doctoral dissertation). University of Georgia, Athens.

Osborne, J. W., Costello, A. B., \& Kellow, J. T. (2008). Best practices in exploratory factor analysis. In J.W. Osborne (Ed.), Best practices in quantitative methods (pp. 8689). Thousand Oaks, CA: Sage Publications.

Ozer, E. M., \& Bandura, A. (1990). Mechanisms governing empowerment effects: A self-efficacy analysis. Journal of Personality and Social Psychology, 58(3), 472-486.

Pinquart, M., Juang, L. P., \& Silbereisen, R. K. (2003). Self-efficacy and successful school-to work transition: A longitudinal study. Journal of Vocational Behavior, 63, 329-346.

Pratt, C. C., McGuigan, W. M., \& Katzev, A. R. (2000). Measuring program outcomes: Using retrospective pretest methodology. American Journal of Evaluation, 21(3), 341-349.

Schyns, B., \& von Collani, G. (2002). A new occupational self-efficacy scale and its relation to personality constructs and organizational variables. European Journal of Work and Organizational Psychology, 11(2), 219-241.

Semmer, N. (2003). Individual differences, work stress and health. In M. J. Schabracq, J. A. M. Winnubst, \& C .L. Cooper (Eds.), Handbook of work and health psychology ( $2^{\text {nd }}$ ed., pp. 83-120). Chichester: John Wiley \& Sons.

Siu, O. L., Lu, C. Q., \& Spector, P. E. (2007). Employees' well-being in Greater China: The direct and moderating effects of general self-efficacy. Applied Psychology: An International Review, 56(2), 288-301.

Smith, B. (2005). Job retention in child welfare: Effects of perceived organizational support, supervisor support, and intrinsic job value. Children and Youth Services Review, 27, 153-169.

Stajkovic, A. D., \& Luthans, F. (1998). Self-efficacy and work-related performance: A meta-analysis. Psychological Bulletin, 124(2), 240-261.

SurveyMonkey [Computer software]. Retrieved from https://www.surveymonkey.com

U.S. Department of Health and Human Services, Administration for Children and Families, Administration on Children, Youth, and Families, Children's Bureau. (2012). Child maltreatment 2011. Available from 
http://www.acf.hhs.gov/programs/cb/research-data-technology/statisticsresearch/child-maltreatment

U.S. General Accounting Office [GAO]. (2003). HHS could play a greater role in helping child welfare agencies recruit and retain staff. Washington, DC: Author.

Wehrmann, K. C., Shin, H., \& Poertner, J. (2002). Transfer of training: An evaluation study. Journal of Health \& Social Policy, 15, 23-37.

Zlotnick, J. L., DePanfilis, D., Daining, C., \& Lane, M. M. (2005). Factors influencing retention of child welfare staff: A systematic review of research. Washington, DC: Institute for the Advancement of Social Work Research. Available from: http://www.socialworkpolicy.org/wp-content/uploads/2007/06/4-CWSRRFinalFullReport.pdf

\section{Author note}

Address correspondence to: Donna J. Cherry, PhD, 203 Lyle House, ETSU, Johnson

City, TN 37614. Email: cherryd@etsu.edu 